\title{
Simulation of Patched Woven Fabric Composite Structures Under Tensile Load
}

\author{
Original Scientific Article
}

Received 03-2016 • Accepted 04-2016

\begin{abstract}
Carbon fibre-reinforced polymers (CFRP) based on woven or non-crimp fabrics are widely used in various industrial sectors such as automotive, aerospace, and wind energy. The demand for repair concepts for these high performance materials is strongly increasing. A new chemical-physical repair method of CFRPs was developed, based on the local removing of the thermoset matrix by energetically activated oxide semiconductors, and the subsequent patch integration and matrix refilling. In the scope of this repair method the design of load-adjusted textile repair patches is a major task. In this paper the design of a textile patch to regain the composites performance is analysed by simulation. Therefore, a finite element (FE) simulation approach based on the domain superposition technique (DST) is used. This approach enables the modelling of a textile reinforcement structure on the mesoscale, while the matrix is modelled on the macroscale. This leads to a high level of detail by a relatively low computational effort.

Keywords: composite repair method, patched composites, domain superposition technique (DST), finite element method (FEM), composite failure modelling
\end{abstract}

\section{Introduction}

The efforts to reduce $\mathrm{CO}_{2}$ emissions are driven, among many other things, by lightweight constructions. The use of carbon fibre-reinforced polymers (CFRP) is gaining importance in several fields of application due to its excellent mechanical properties at little weight. The damage of these composite materials, such as delamination, debonding, fibre or matrix breakage, is an increasing concern. Therefore, the demand for appropriate repairing concepts is getting in the focus of investigation. Mostly damaged components are replaced and rarely repaired. A currently applied repair procedure is the scarf method. The damaged area is removed by mechanical abrasion (e.g. milling) and a metal sheet or carbon fibre patch is inserted $[1,2]$. A new chemicalphysical repair method for CFRP by the use of oxide semiconductors (OSC) was previously presented [3]. In this method the thermoset matrix is locally removed by applying an OSC in the damaged area.

Corresponding author:

Dipl.-Ing. Matthias Hübner

Phone: +4935146342244

E-mail: matthias.huebner1@tu-dresden.de
The matrix is completely removed by heat-indicated activation of the catalyst. Afterwards the damaged fibres are removed and a load-adjusted repair patch is inserted. The composite structure is reconstructed by refilling with the thermoset matrix.

Designing the required load and geometry adjusted repair patches based on finite element (FE) simulations to regain the composite performance is envisaged due to a reduced trial-and-error design phase. For the simulation the domain superposition technique (DST) offers many advantages. All reinforcement layers are considered individually and the best geometry for each layer of the repair patch can be designed. Moutoussamy et al. [4] applied the DST for the simulation of steel rebars in concretes. Jiang and Hallet $[5,6]$ presented the DST for the simulation of woven textile reinforcements in composites. Pure mesoscale and microscale models of composites as shown in $[7,8]$ are characterised by complex modelling and high computational effort and are particularly useful for unit cell simulations.

Tekstilec, 2016, 59(2), 175-181

DOI: 10.14502/Tekstilec2016.59.175-181 


\section{Experimental}

\subsection{Materials}

The reinforcement structure used for the investigations was a twill woven fabric (KDK-8004 by Carbon Werke Weißgerber GmbH \& Co KG) made of $12 \mathrm{~K}$ (800 tex) carbon fibres. The fabric properties are shown in Table 1. The breaking force and elongation at break were determined according to ISO 4606 [9].

The resin used for the composite production was EPIKOTE Resin MGS RIMR 135 with EPIKURE curing agent MGS RIMH 134 (by HEXION Inc.) with the properties shown in Table 2. For the determination of standard composite properties, the tensile test (according to DIN EN ISO 527-4 [10]) and an inter-laminar shear test (according to DIN EN 2563 [11]) were performed. The results are shown in Table 3.

\subsection{Repair Method}

For the local matrix degradation in the damaged area oxide semiconductors (OSC, i. e. $\mathrm{Cr}_{2} \mathrm{O}_{3}, \mathrm{CeO}_{2}$, $\mathrm{NiO}, \mathrm{TiO}_{2}$ ) were used [3]. By utilizing a mask the OSC powder was applied on the composite and activated with an IR-lamp. The best results could be achieved with $\mathrm{Cr}_{2} \mathrm{O}_{3}$, where the matrix degradation of a $2 \mathrm{~mm}$ thick composite takes about 8-10 min. Figure 1 shows the experimental set up for the local matrix degradation.

After locally removing the matrix and the damaged fibres a reinforcement patch is inserted. The geometry and load-adjusted design of the patch is very important to regain the composite performance. In the last step the matrix was refilled using an epoxy resin and the SCIMP-method (Seeman Composites Resin Infusion Molding Process).

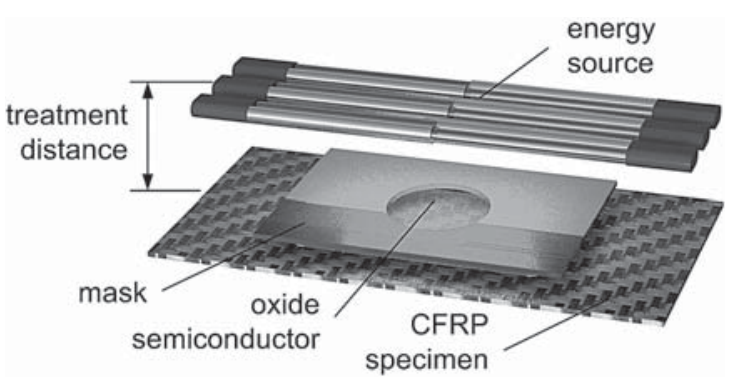

Figure 1: Experimental set up for local matrix degradation

\subsection{Simulation Method}

The simulation model for the load-adjusted patch design has to fulfil crucial requirements, i.e. the representation of the textile reinforcement structure, a

Table 1: Properties of the reinforcement structure

\begin{tabular}{|c|c|c|c|c|c|c|}
\hline \multirow{2}{*}{$\begin{array}{c}\text { Area weight } \\
{\left[\mathrm{g} / \mathrm{m}^{2}\right]}\end{array}$} & \multicolumn{2}{|c|}{ Fibre density [fibres $/ \mathrm{cm}]$} & \multicolumn{2}{c|}{ Breaking force $[\mathrm{N} / \mathrm{cm}]$} & \multicolumn{2}{c|}{ Elongation at break ${ }^{\star}[\%]$} \\
\cline { 2 - 7 } & warp & weft & warp & weft & warp & weft \\
\hline 650 & 4 & 4 & 2740 & 2680 & 2.2 & 2.2 \\
\hline
\end{tabular}

${ }^{*}$ ISO 4606

Table 2: Properties of the resin system

\begin{tabular}{|c|c|c|c|c|}
\hline $\begin{array}{c}\text { Density } \\
{\left[\mathrm{g} / \mathrm{cm}^{3}\right]}\end{array}$ & $\begin{array}{c}\text { Young's modulus } \\
{[\mathrm{GPa}]}\end{array}$ & $\begin{array}{c}\text { Tensile strength } \\
{[\mathrm{MPa}]}\end{array}$ & $\begin{array}{c}\text { Compressive } \\
\text { strength } \\
{[\mathrm{MPa}]}\end{array}$ & $\begin{array}{c}\text { Elongation at } \\
\text { break } \\
{[\%]}\end{array}$ \\
\hline 1.18 & 3.2 & 75 & 90 & $8-16$ \\
\hline
\end{tabular}

Table 3: Properties of the composite

\begin{tabular}{|c|c|c|c|c|c|c|c|c|}
\hline $\begin{array}{c}\text { Young's modulus } \\
{[\mathrm{GPa}]}\end{array}$ & $\begin{array}{c}\text { Breaking force } \\
{[\mathrm{N} / \mathrm{cm}]}\end{array}$ & \multicolumn{2}{|c|}{$\begin{array}{c}\text { Elongation } \\
\text { at break } \\
{[\%]}\end{array}$} & \multicolumn{2}{|c|}{$\begin{array}{c}\text { Tensile strength } \\
{[\mathrm{MPa}]}\end{array}$} & $\begin{array}{c}\text { Inter-laminar } \\
\text { shear strength } \\
{[\mathrm{MPa}]}\end{array}$ \\
\hline warp & weft & warp & weft & warp & weft & warp & weft & \\
\hline 38 & 34 & 8970 & 8400 & 1.28 & 1.23 & 446 & 410 & 42.1 \\
\hline
\end{tabular}

*DIN EN ISO 527-4, ** DIN EN 2563 
high adaptability for the patch geometry modelling and a reasonable modelling and computational effort. For this, analysis methods which neglect the reinforcement layer stacking cannot predict the required stress- and strain distribution. The domain superposition technique (DST) introduced by Jiang et al. [5] is very promising for the modelling of repair patches. Thereby the textile reinforcement structure is modelled on the mesoscale embedded in a solid element mesh of the matrix, whereby the number of elements and the model size are reduced.

\section{Textile Reinforcement Model}

The textile reinforcement structure was modelled on the mesoscale, where the yarns were represented by shell elements. In order to achieve a realistic representation of the yarn geometry and to avoid penetrations the shell element thickness was adapted (Figure 2a). Figure 2b shows the geometry model of the twill woven fabric, generated in accordance with the method described in [12] for digital element chains. The dimensions were determined by analysing a micro-section. For the mechanical behaviour of the reinforcement yarns a user defined material model was used in LS Dyna [13]. Furthermore, the

\section{equal shell thickness}

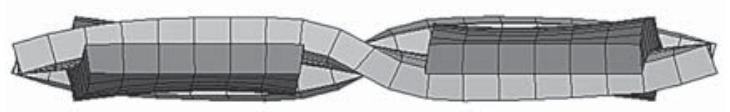

adjusted shell thickness

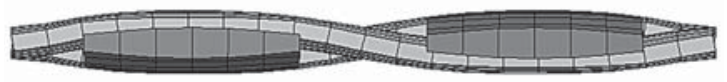

a)

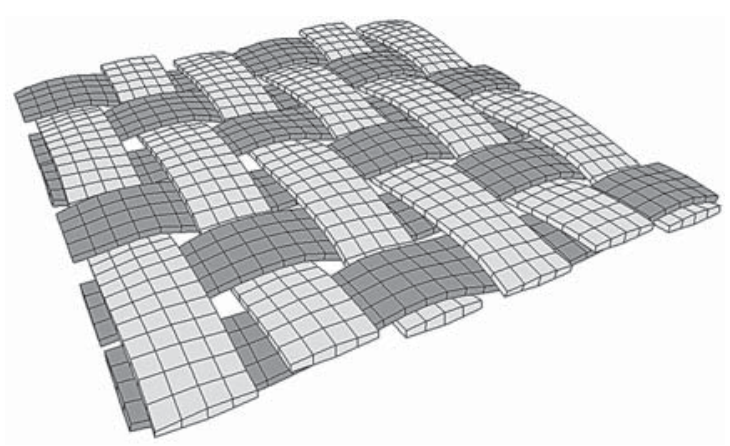

b)

Figure 2: Mesoscale model of the textile reinforcement: (a) yarn cross section by adjusting the shell thickness, (b) mesoscale model of twill woven fabric low bending stiffness of the yarns was taken into account by layered shell elements with adjusted material properties of the single layers. This mesoscale modelling approach is easily adaptable to various reinforcement structures and can also be used for drape or forming simulations.

\section{Composite model}

The shown model of the textile reinforcement was embedded in a matrix mesh. By using the DST, the matrix was not modelled explicitly, instead a global mesh was used. Under tensile load of the patched composites the delamination mode I (shear) and mode II (tearing or twist) occur. The failure of the matrix was realized in the matrix material model by implementing a tensile and a shear stress based failure criterion. The required inter-laminar shear stress parameters are determined according to standard DIN EN 2563:1997. Furthermore, the fibre pull-out was realised in the model with cohesive elements (nullshells). The nullshells were kinematically constrained to the matrix mesh and the elements of the reinforcement structure were coupled to the nullshells with defined interface normal and shear failure stresses.

Figure 3 shows exemplarily a composite model with two layers of twill woven fabric and the matrix mesh (blue). In a previous simulation step the two textile layers are compacted to get the final composite thickness and to represent the interaction of the yarns. With this kind of simulation approach it became possible to model single layers of the textile reinforcement and the interaction with the matrix. Thus, the optimal geometry and overlap length of the repair patch can be designed to restore the composite performance completely.

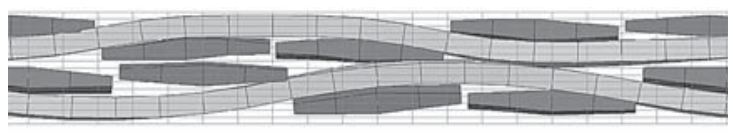

Figure 3: Scheme of the composite model

The simulation model, especially the elastic and failure behaviour of the composite, was validated with the tensile test according to DIN EN ISO 527-4 and the open-hole tensile test. The dimensions of the open-hole specimens were $50 \mathrm{~mm} \times 150 \mathrm{~mm}$ with an open hole diameter of $20 \mathrm{~mm}$. The dimensions of the specimen differ from ASTM D5766/D5766M in order to use them as reference for the benchmark of the repair method. 


\subsection{Repair Patch Design}

For the design of the repair patch a uniform stress distribution and the transferable stresses are most important. Under tensile load the delamination mode I (shear) and mode II (tearing or twist) and thus inter-laminar shear stress occurs. Thus, the transmittable inter-laminar shear stress in the patched area must be at least as high as the tensile strength of the composite.

For the design of the repair patches the two layered open-hole specimen was defined as a damaged composite. Two different patch designs are discussed. Patch 1 is a "step lap joint" with a ply per ply overlap and patch 2 is an adapted patch with a higher structural integrity (Figure 4). Therefore, the original structure and the patches were adapted to the tensile load case [14]. The fibres oriented perpendicular to the tensile direction were removed from the textile structure. In this case a symmetrical patch design became possible without thickening the composite. Furthermore, the number of load carrying fibres was increased in the overlapping area.

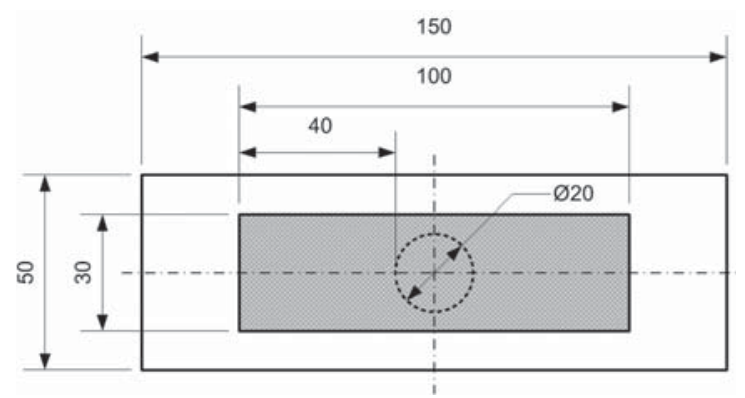

a)

Patch 1

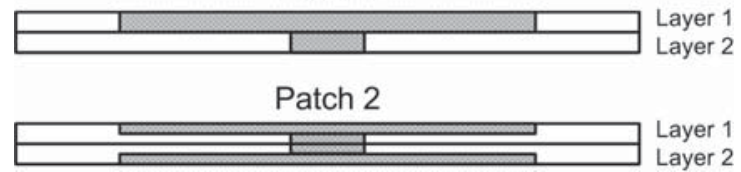

b)

Figure 4: Different repair patch designs: (a) top view (patch is blue), (b) section view: patch 1 and 2

\section{Results and Discussion}

\subsection{Model Validation and Composite Simulation}

\section{Simulation of the Tensile Test}

The first validation case of the composite model is the simulation of the tensile test without any holes according to DIN EN ISO 527-4. The simulation shows excellent agreement with the experiments regarding tensile modulus, breaking force, and elongation at break (Figure 5a). Figure 5b shows the forceelongation curves determined experimentally and numerically under tension load. The failure of the composite in the simulation is indicated by the slope of the force curve at about $1.24 \%$ elongation at a force of about $23 \mathrm{kN}$ (tensile strength $460 \mathrm{MPa}$ ).

\begin{tabular}{|l|c|c|}
\hline & Simulation & Experiment \\
\hline $\begin{array}{l}\text { Young's modulus } \\
\text { [GPa] }\end{array}$ & $\begin{array}{c}36.1 \\
(6.5 \%)^{*}\end{array}$ & 38.4 \\
\hline $\begin{array}{l}\text { Breaking force } \\
\text { [N/cm] }\end{array}$ & $\begin{array}{c}9200 \\
(2.4 \%)^{*}\end{array}$ & 8976 \\
\hline $\begin{array}{l}\text { Elongation at } \\
\text { break [\%] }\end{array}$ & $\begin{array}{c}1.24 \\
(3.2 \%)^{*}\end{array}$ & 1.28 \\
\hline $\begin{array}{l}\text { Tensile strength } \\
\text { [MPa] }\end{array}$ & $\begin{array}{c}460 \\
(3.1 \%)^{*}\end{array}$ & 446 \\
\hline
\end{tabular}

*deviation to experiment

a)

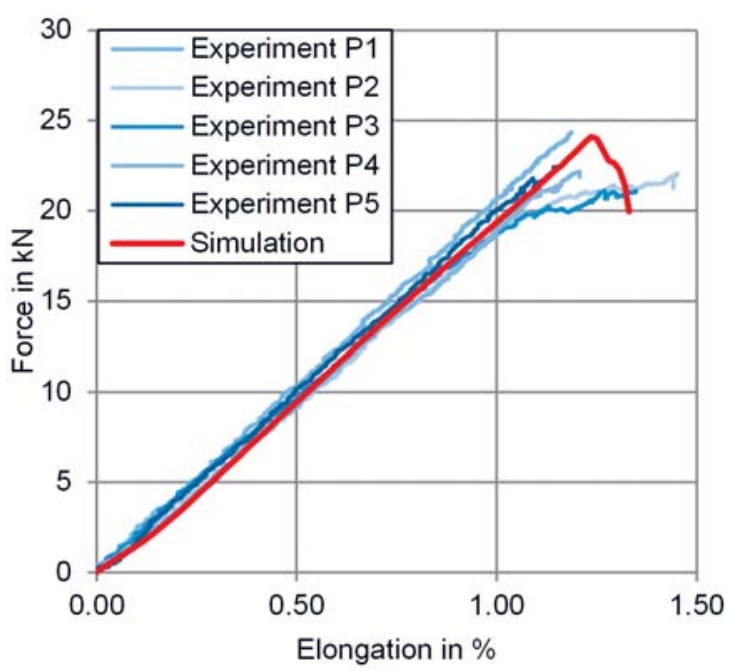

b)

Figure 5: Tensile test simulation results: (a) simulation and experimental data, (b) force elongation curve

\section{Simulation of the Open-Hole Specimen}

The second case is the simulation of the open-hole specimen under tension load. Also a very good correlation between the experiment and the simulation results was achieved. The breaking force in the experiment was about $23.1 \mathrm{kN}$ and in the simulation 
about $22.5 \mathrm{kN}$. Figure 6a shows the von Mises stress (equivalent stress) in the matrix just before and after the failure and Figure $6 \mathrm{~b}$ shows the failed specimen from the experiment.

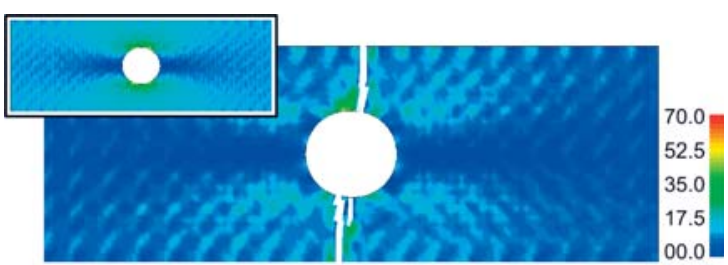

a)

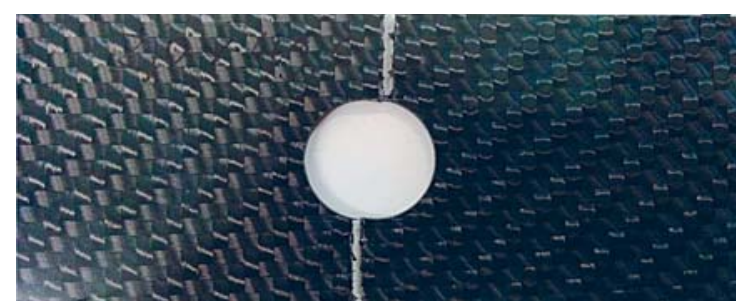

b)

Figure 6: Simulation of the open-hole specimen: (a) simulation (von Mises stress [MPa] in matrix), (b) failed specimen

The simulation results show the applicability of the selected simulation approach based on the DST. For the investigated composite a very good agreement between experiment and simulation in terms of tensile and failure behaviour was achieved.

\subsection{Simulation of Patched Composites}

For the simulation of the patched composites two models based on the open-hole specimen were created. In a supplementary simulation step the geometric models of the patches are integrated in the existing model of the reinforcement. Figure 7 shows the model of the textile reinforcement of patch design 2 . Figure 8 shows the non-uniform strain distribution in the patched composite samples. The maximum

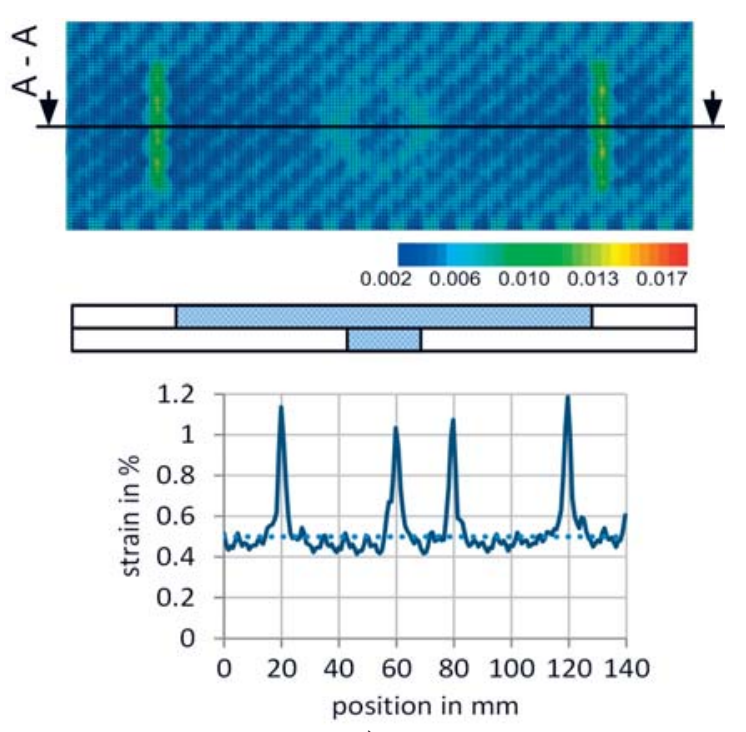

a)
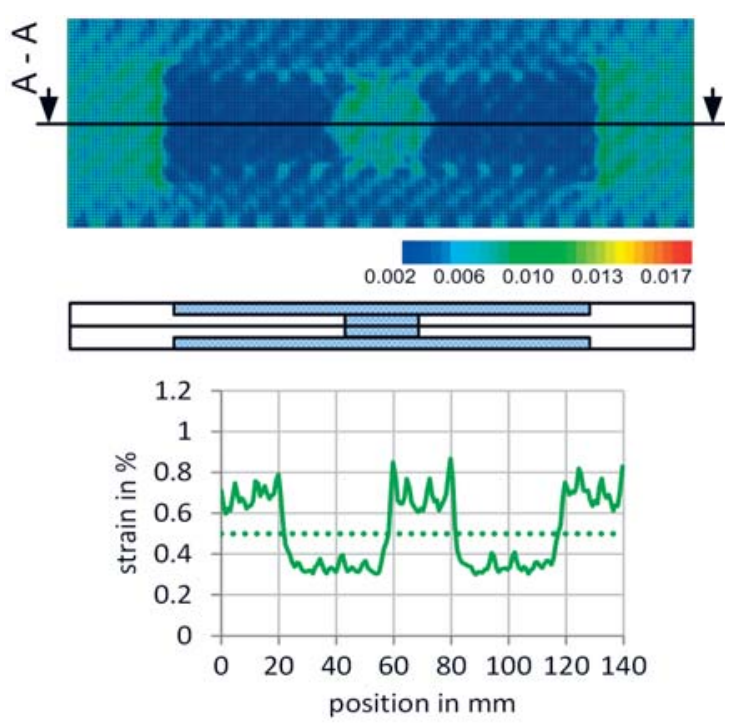

b)

Figure 8: Strain distribution in different patched specimens (total strain 0.5\%): (a) patch design 1, (b) patch design 2

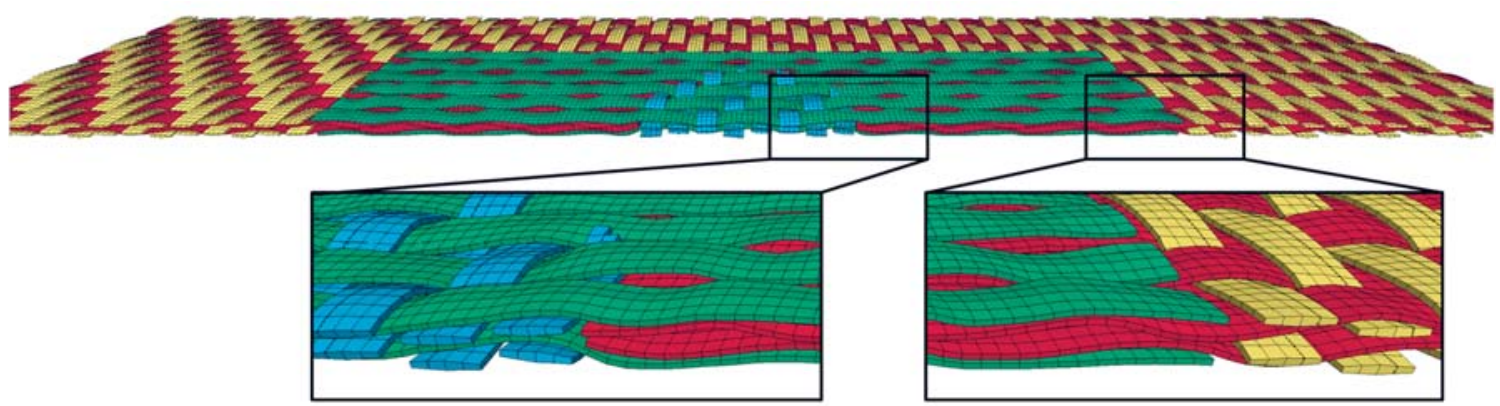

Figure 7: Patch 2 - mesoscale model of the textile (one half of the symmetric problem) 
strain profile across the middle surface of the specimen clearly indicates the local strain/stress peaks. At a total elongation of the specimen of $0.5 \%$ already local strains of $1.69 \%$ (stress $52.3 \mathrm{MPa}$ ) in patch design 1 and 1.32\% (stress $48.8 \mathrm{MPa}$ ) in patch design 2 occur in the specimen. These stress peaks in the transition area indicate the beginning of the failure. Compared to patch design 1, the stress peaks are reduced significantly with patch design 2 . This can also be seen in the breaking forces of the specimens. With patch design 1 the specimen breaks at a load of $22.5 \mathrm{kN}$ and with patch design 2 the specimen breaks at $40.8 \mathrm{kN}$. The advantageous stress and strain distribution with patch 2 is caused by the high structural integrity (2.4). In the patched area (between $20-60 \mathrm{~mm}$ and $80-120 \mathrm{~mm}$ ) the fibre volume fraction is higher, which results in a lower strain (Figure 8b). The design of the transition zone between the original structure and the repair patch prevents the stress peaks. With patch design 2 excellent repair results can be achieved, the breaking force under tensile load was about $89 \%$ of the undamaged reference specimen.

\subsection{Repair Method}

The local matrix degradation was successful [3]. An optically evaluation shows that the specimen is locally resin free after local removing of the matrix. The treated area is undamaged and unaffected by the chemical-physical treatment of the process. Figure 9 shows the rectangular resin free area of the open-hole specimen and a specimen with an integrated repair patch after matrix refilling. The general suitability of the chemical-physical local repair procedure was demonstrated.

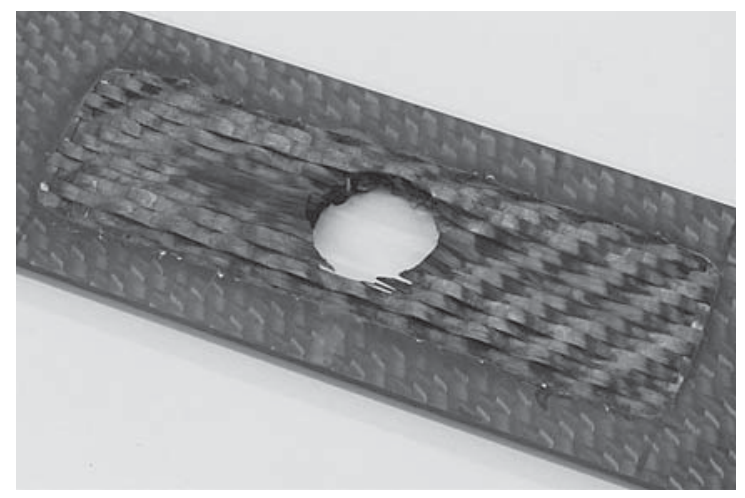

a

\section{Conclusion}

A novel repair method for CFRPs based on the local matrix degradation was presented. For the design of load- and geometry-adjusted repair patches the FEsimulation was used. To take into account the structure of the textile reinforcement and the patch an adaptable mesoscale model was applied. With the domain superposition technique (DST) the computational effort was reduced, whereby the matrix was not explicitly modelled. The simulation model also considered the fibre and matrix failure as well as fibre-matrix debonding. First simulations with different patch geometries showed that about $90 \%$ of the composite performance under tensile load can be restored by the integration of a load-adjusted repair patch. Thus, this method is suitable as a repair concept for CFRP structures.

\section{Acknowledgements}

The authors would like to thank the German Research Foundation (DFG) for the financial support of the research activities in the scope of the projects DFG CH 174/36-1 and DFG HU 2107/4-1.

The authors also would like to thank the European Union Regional Development Fund (EFRE) and the Free State of Saxony for the funding.

\section{References}

1. HARMAN, Alex B., WANG, Chun H. Improved design methods for scarf repairs to highly strained composite aircraft structure. Composite

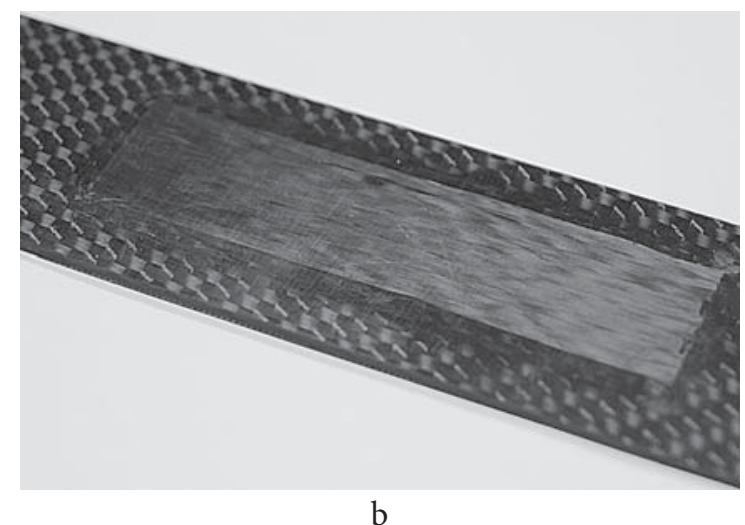

b

Figure 9: CFRP after removing the thermoset matrix and repair procedure: (a) locally removed matrix, (b) integrated patch 2 and refilled matrix 
Structures, 2006, 75(1-4), 132-144, doi: 10.1016/ j.compstruct.2006.04.091.

2. BORGMAN, Michael. Bonded repair: Design and process considerations. Commercial Aircraft Composite Repair Committee (CACRC) Meeting and Related Industry/FAA/EASA Workshop. Amsterdam, Netherlands. 2007 [online] [accessed 15. 3.2016]. Available on World Wide Web: <https://www.niar.wichita.edu/niarworkshops/ Portals/0/Thursday\%20May\%2010\%20430\%20 Borgman.pdf $>$.

3. KÜCHLER, Kristin, STAIGER, Elias, HUND, Rolf Dieter, DIESTEL, Olaf, KIRSTEN, Martin, CHERIF, Chokri. Local repair procedure for carbon fiber reinforced plastics by refilling with thermoset matrix. Applied Journal of Polymer Science, 2015 133(6), doi: 0.1002/app.42964.

4. MOUTOUSSAMY, L., HERVE, G., BARBIER, F. Qualification of constrained_Lagrange in solid command for steel/concrete interface modelling. In: Proceedings of the $8^{\text {th }}$ European LS-Dyna Conference, Strasbourg, France, 2011, [online] [accessed 29. 3. 2016] Available on World Wide Web: <www.dynamore.de/de/download/papers/ konferenz11/papers/session12-paper3.pdf $>$.

5. JIANG, Wen-Guang, HALLET, Stephen R., WISNOM, Michael R. Development of domain superposition technique for the modelling of woven fabric composites. Mechanical Response of Composites, 2008, 10 (Computational Methods in Applied Sciences), 281-291, doi.org/10.1007/ 978-1-4020-8584-0 14.

6. HALLETT, S. R., BIRAGONI, P. Damage prediction for 3D woven composite structural features. In: Recent Advances in Textile Composites. Proceedings of the $10^{\text {th }}$ International Conference on Textile Composites: (TEXCOMP10). Edited by Christophe Binetruy and François Boussu. Lancaster, Pensilvania : DEStech Publications, 2010, 36-43.

7. LOMOV, Stepan V., IVANOV, Dmitry S., VERPOEST, Ignaas, ZAKO, Masaru, KURASHIKI,
Tetsusei, NAKAI, Hiroaki, HIROSAWA, Satoru. Meso-FE modelling of textile composites: Road map, data flow and algorithms. Composites Science and Technology, 2007, 67(9), doi:10.1016/j. compscitech.2006.10.017.

8. BEDNARCYK, Brett A., STIER, Bertram, SIMON, Jaan-Willem, REESE, Stefanie, PINEDA, Evan. J. Meso- and micro-scale modeling of damage in plain weave composites. Composite Structures, 2015, 121. 258-270, doi:10.1016/j. compstruct.2014.11.013.

9. Textile glass - Woven fabric - Determination of tensile breaking force and elongation at break by the strip method, ISO 4606:1995.

10. Plastics - Determination of tensile properties Part 4: Test conditions for isotropic and orthotropic fibre-reinforced plastic composites, ISO 527-4:1997.

11. Aerospace series - Carbon fibre reinforced plastics - Unidirectional laminates; determination of apparent interlaminar shear strength, DIN EN 2563:1997.

12. DÖBRICH, Oliver, GEREKE, Thomas, CHERIF Chokri. Modelling the mechanical properties of textile-reinforced composites with a near micro-scale approach. Composites Structures, 2016, 135, 1-7, doi: 10.1016/j.compstruct.2015.09.010.

13. HÜBNER, M., STAIGER, E., GEREKE, T., CHERIF, C. Simulation-based development of tailored CFRP-Repair patches. In: Proceeding of the 5th ECCOMAS: Thematic Conference on $\mathrm{Me}$ chanical Response of Composites (Composites 2015). Bristol, UK, 2015.

14. STAIGER, E., KÜCHLER, K., HÜBNER, M., HUND, R.-D., KIRSTEN, M., GEREKE, Thomas, CHERIF, Chokri. Complete local removal of the thermoset matrix as the basis of developing an innovative, new repair method for carbon fiber reinforced plastics. In: Proceedings of the 4th international conference on Thermosets Thermosets 2015: From Monomers to Components. Berlin, Germany. 2015. 